unrealistic if many, if not most, of the key actors across the world were not prepared to make a significant sacrifice. That sacrifice is measured in both time and money. We're all almost certainly far too busy for our own good, for that of our families, and for those we serve. Most of us are also experiencing the worldwide recession that makes it very difficult to find $\$ 100$ to invest in a society membership, or even slightly less for a subscription to the journal. In some countries, the amount being asked must seen exceptionally formidable, and I hope eventually we will be able to take this into account. But until then, there is nothing else I can do than to plead with each of you to swallow hard, dig deep (and invoke any other mixed metaphors you can think of) to make the sacrifice to become a full time player on this winning team. With a hundred new members and a similar number of subscribers, we will certainly have achieved the critical mass necessary to permit our voices to be heard on behalf of child safety everywhere.

\title{
Three more reasons why you should go to Melbourne
}

This next bit may appear as if I'm serving as a travel agent or running a tourist bureau. Neither is too far from the truth because my intention is to convince you that attending the next International Congress in Melbourne will be not only intellectually rewarding but also good for the body and soul. About 10 years ago, I had the privilege of spending a hectic week in Melbourne as the Felton Visiting Professor. Despite my exhaustion from the visit's lecturing requirements, I immediately fell in love with the city and its environs. The only other city outside of Europe that has an equally cosmopolitan flavour is, of course, Montreal. Melbourne, however, has the added advantage of glorious beaches, great scenery, and plants and wildlife unlike anything any North American or most Europeans have ever seen. So even if you aren't the least interested in the professional part of this trip, it's a marvellous vacation, and although it costs a small bundle for most of us, think of it as a once in a lifetime opportunity to see a magnificent part of the world.

But also think of the trip as an important chance to improve your injury prevention effectiveness. The most valuable aspect of any such meeting for me is unvariably the people I meet. It is the corridor conversations rather than the formal presentations that I treasure. Being able to put a face to the name of someone with whom you later correspond, or whose papers you later read, is an entirely unique experience.

Finally, apart from these valuable casual encounters, there will be formal presentations and the ISCAIP meeting. The program makes it clear that there will be something of interest for everyone, culminating in the special program for those involved with children and adolescents. So save your pennies and book your flight.

\section{End of term report card}

At the end of each volume many journals provide a report card for their readers. Ours will be brief. Were this a real report card, I hope the teacher's comments would read something like, 'Making progress - keep up the good work'. Between the official starting date, 1 September 1994, and the same date in 1995, we have received 66 papers. All but four were sent to at least two reviewers. No manuscript was recommended for publication without requesting either minor or major revisions. Twenty five were published in the first volume and many more are still pending.

Most published papers came from academic settings; a few were from health departments; and very few from service programs. The countries of origin include: Australia, Canada, England, France, Greece, Ireland, Israel, New Zealand, South Africa, Sweden, United States, and Wales. A majority of contributors were medical or nonmedical epidemiologists; but the list includes dentistry, nursing, psychology, public health, general practice, maternal and child health, and health economics. Thus, we have achieved the diversity of both disciplines and countries we had hoped for.

Particular thanks are due to the anonymous reviewers listed on p 214. For the most part, referees' comments were not only detailed and constructive but, also, as a rule, prompt. The average lag between sending a paper for review and receiving a reply was about four weeks; far better than most journals. (This is a special accomplishment in light of the notorious inefficiency of Her Majesty's Postal 'Service' in Canada.) Each reviewer deserves the gratitude of the editorial board, as well as (I hope) the contributors. The journal could not function without these 'unsung' contributions. 